\title{
Clinical Presentation of Painful Musculoskeletal Conditions at Community Level
}

\author{
Md Zahangir Alam ${ }^{1}$ \\ Mohammad Moin Uddin ${ }^{2 *}$ \\ Aminuddin A Khan ${ }^{2}$ \\ Shawkat Hossain ${ }^{2}$ \\ Md Abdul Jalil ${ }^{3}$
}

${ }^{1}$ Department of Physical Medicine and Rehabilitation Chattagram Maa Shishu-O-Genaral Hospital Chittagong, Bangladesh.

${ }^{2}$ Department of Physical Medicine and Rehabilitation Chittagong Medical College

Chittagong, Bangladesh.

${ }^{3}$ Department of Cardiologist Chittagong General Hospital Chittagong, Bangladesh.
*Correspondence to:

\section{Dr. Mohammad Moin Uddin} Consultant

Department of Physical Medicine and Rehabilitation Chittagong Medical College Hospital

Chittagong, Bangladesh.

Mobile : +8801711159038

Email : moinmonju@gmail.com

www.banglajol.info/index.php/CMOSHMCJ

\begin{abstract}
Background: This study was done in the community level to investigate the frequency of clinical manifestations of painful musculoskeletal conditions that present to the primary care physicians and to see the variations of musculoskeletal diseases in relations to age, gender and occupation. Methods: This was a crosssectional study. People with painful musculoskeletal conditions included and data were collected once. 107 patients with pain and musculoskeletal complaints were included in this study. Results: Majority (44.85\%) presented with back pain. The commonest type of disease was degenerative (51.40\%).15 cases (14.02\%) of musculoskeletal pain were of inflammatory type. Peak age at presentation of musculoskeletal diseases was 40-49 years, which included $23.36 \%$ of total participants. $57.94 \%$ of the patients with musculoskeletal diseases were females. Among people of all occupations housewives constituted 52.33\%. Conclusions: Low back pain is found as the commonest painful musculoskeletal problem encountered by the primary care physicians. Neck and shoulder pains are the next common problems. Housewives are the most vulnerable to musculoskeletal problems. A considerable number of inflammatory musculoskeletal diseases are also present at primary care level.
\end{abstract}

Key words: Pain; Musculoskeletal; Rheumatic diseases; Primary care.

\section{INTRODUCTION}

Musculoskeletal (MSK) problems are very common causes of disability within the community ${ }^{1}$. Majority of Musculoskeletal conditions are seen at the level of general practitioner $^{1}$. Although we have some ideas about Musculoskeletal diseases at tertiary level, enough knowledge still lacks at the community level ${ }^{2}$. Approximately a quarter of patients attending a general and outpatient clinic have musculoskeletal system-related complaints ${ }^{3}$.

GP doctors frequently face difficulties because; they do not possess the required attitude, skills and knowledge to asses clinically such (Musculoskeletal) patients. These diseases are neglected by everyone ${ }^{4-7}$. Hence, knowledge of the patterns of manifestations is a crucial need for their early diagnosis, accurate treatment and initiation of preventive measures.

MSK diseases increase with age ${ }^{8}$. Nearly three in 10 of those over 75 years, are in chronic pain due to arthritis ${ }^{9}$. Moreover, females $(57.1 \%)$ are more prone to musculoskeletal diseases than males $(42.9 \%)^{10}$. Determination of variations in the presentations of musculoskeletal symptoms along with risk group allocation in the context of our community is important for better management. 
The main objectives of this study is to sought out the clinical presentations of various painful musculoskeletal conditions at community level, to make an assumption about the bulk of inflammatory conditions and serious diseases so as to emphasize on their diagnosis and management.

\section{METHODS AND MATERIALS}

This was a cross sectional study. Data were collected at Anowara Upazilla Health Complex (A primary health care centre) Chittagong. The outpatient department of the health complex deals with average 300 to 350 patients per day. Patients of all ages and both gender complaining of musculoskeletal pain were included. Those with nonmusculoskeletal pain were excluded. Patients unwilling to participate were also excluded. Prior to the data collection, announcement was made for patients with pain to attend the health complex for treatment by specialist team. History of the patients, attending the out-patient department of a primary health complex was taken. There were lots of patients in outpatient department with complaints other than pain. From total 411 patients, those with musculoskeletal complaints were screened out. Then they were thoroughly examined clinically to detect the sites of pain, types of diseases before data collection. Patients with pain from non-musculoskeletal origin were excluded. Finally, 107 patients were selected for study. A semi-structured questionnaire was filled by the researchers. Data were collected from the history, the examination findings and after necessary investigations.

\section{RESULTS}

From 107 patients, $62(57.94 \%)$ were females and 45 $(43.06 \%)$ were males. $45.79 \%$ patients presented with back pain. Other common presentations were knee pain $(22.4 \%) \&$ neck pain (12.14\%), (Table 1). Commonest age group of the patients with musculoskeletal symptoms was 40-49 years (23.36\%) and 50-59years $22.42 \%$ (Table 3). 80 (74\%) patients had musculoskeletal disease of mechanical category. Fifteen patients (14.02\%) had of inflammatory type of musculoskeletal diseases (Table 2). 52.34\% patients were housewives who presented with musculoskeletal symptoms. From 107 patients, 50 patients (45.79\%) came with back pain, of which 49 (98\%) presented with Low Back Pain (LBP) and one (2\%) with Upper back pain. Most common age group in LBP patients was 50-59, which comprised $23.53 \%$. Other age groups at risk are $40-49$ yrs (20.40\%), 30-39 yrs (20.40\%), 20-29 yrs (14.28\%) (Table 4). $53.06 \%$ LBP patients were housewives. Of 107 musculoskeletal pain patients, $2^{\text {nd }}$ most common $(22.4 \%)$ manifestation was knee pain. $75 \%$ of all knee pain patients were females and $25 \%$ were males. Most common age group suffered from knee pain was $40-59(59.09 \%)$,
Table 1: Clinical presentation of musculoskeletal diseases.

$\begin{array}{lllcc}\text { Clinical presentations } & \mathbf{N} & \% & \text { Female (\%) } & \text { Male (\%) } \\ \text { Low back pain } & 49 & 46 & 15 & 31 \\ \text { Knee pain } & 24 & 22 & 17 & 06 \\ \text { Neck pain } & 13 & 12 & 02 & 10 \\ \text { Ankle or foot pain } & 09 & 08 & 03 & 07 \\ \text { Shoulder pain } & 08 & 07 & 07 & 02 \\ \text { Pain in whole body } & 08 & 07 & 00 & 07 \\ \text { Elbow pain } & 04 & 03 & 01 & 03 \\ \text { Pain in wrist or hand } & 05 & 05 & 02 & 03 \\ \text { Calf pain } & 03 & 03 & 00 & 03 \\ \text { Upper back pain } & 01 & 01 & 00 & 01\end{array}$

Table 2 : Clinical varieties of musculoskeletal diseases.

\begin{tabular}{lcc} 
Patterns & Number & Percentage \\
Mechanical & 80 & 74 \\
Soft tissue rheumatism & 12 & 11 \\
Inflammatory & 15 & 14 \\
Others & 09 & 09 \\
\hline
\end{tabular}

Table 3 : Age and Gender Distribution of Patients with Musculoskeletal Diseases.

\begin{tabular}{lrrrc} 
Age & No. & $\%$ & Male $(\mathbf{M})$ & Female (F) \\
$<19$ & 2 & 1.9 & $0.9 \%$ & $0.9 \%$ \\
$20-29$ & 15 & 14.0 & $1.9 \%$ & $12.1 \%$ \\
$30-39$ & 21 & 19.6 & $5.6 \%$ & $14.0 \%$ \\
$40-49$ & 25 & 23.4 & $7.5 \%$ & $15.9 \%$ \\
$50-59$ & 24 & 22.4 & $11.2 \%$ & $11.2 \%$ \\
$60-69$ & 15 & 14.0 & $5.6 \%$ & $8.4 \%$ \\
$70-79$ & 4 & 3.7 & $0.9 \%$ & $2.8 \%$ \\
$>80$ & 1 & 0.9 & 0 & $0.9 \%$ \\
\hline
\end{tabular}

Table 4 : Common Occupations of Patients with musculoskeletal Diseases.

\begin{tabular}{lrc} 
Occupation & No. of case & Percentage \\
Farmer & 12 & 11.2 \\
Businessman & 5 & 4.7 \\
Office worker & 12 & 11.2 \\
Housewife & 56 & 52.3 \\
Day labourer & 4 & 3.7 \\
Others & 18 & 16.8 \\
\hline
\end{tabular}




\section{DISCUSSION}

Hundred seven (107) patients with MSK complaints were included in the study. The most prevalent presentation was back pain, prevailing in $46.72 \%$ of all patients. In another study, back pain prevalence was found in $30-40 \%$ of the adults ${ }^{11}$. Our result is almost consistent with that. Another study shows back pain in $59 \%$ subjects $^{12}$. The $2^{\text {nd }}$ commonest MSK diseases manifestation was knee pain which comprises $22.41 \%$. This value is to some extent higher than rate, which is $10-15 \%$ found in a study abroad ${ }^{11}$.

Females were more sufferers from MSK diseases than males which are also found in almost all other studies. $66.35 \%$ were females where as $33.64 \%$ were males in our result, that is nearly similar with a survey result (Showing $57.1 \%$ females \& $42.90 \%$ males $)^{10}$. Studies showed that women with joint pain (i.e. O.A) have high level of free estrogen and the estrogen may be chondrodestructive ${ }^{13,14}$. This might be the reason why women suffer more.

This study also proved that, MSK diseases increase with age and are found most common (23.36\%) in 40-49 age group and second most common $(22.42 \%)$ in $50-59$ age group ${ }^{8}$. This higher incidence may be due to presence of degenerative diseases and osteoporosis which are age related ${ }^{15}$.
Most (52.33\%) of the MSK patients were housewives and farmers who suffered principally from back pain $(33.06 \%$, $18.36 \%$ respectively) and knee pain (63.64\%, 9.09\% respectively). This might be due to prolonged knee bending and forward stooping position related to their household activities. MSK diseases were much less common (3.73\%) in day labourers.

\section{ACKNOWLEDGEMENTS}

We express our thanks to the patients for their consent and cooperation. We are also grateful to the rehabilitation team members for their assistance in data collection. Special gratitude for the Anowara Upazilla Health and family Planning Officer (UH \& FPO) and doctors for their kind hospitality.

\section{CONCLUSION}

MSK diseases represent to primary care physicians in various forms. Low back pain is found as the commonest problem for the villagers particularly, housewives. A considerable number inflammatory MSK diseases are also present which needs the attention of the specialists. Moreover, study with larger sample size or multicentre (At many Upazillas) studies are required in future for a better picture.

\section{DISCLOSURE}

All the authors declared no competing interest.

\section{REFERENCES}

1 Dacre JE, Griffith SM, Jolly BC. Rheumatology \& Medical Eduction in Great Britain, British Journal of Rheumatology. 1996; $35: 269-274$.

2 Lawrence RC, Helmick CG, Arnett FC, et al. Estimates of the prevalence of arthritis \& selected MSK disorders in the United States. Arthritis Rheum. 1998; 41: 778-799.

3 Dequeker J, Rasker JJ, Wolf AD Educational issues in Rheumatology. Bailliere's Best Pract Res ClinRheumatol. 2000; 14: 715-729.

4 Dequeker J, Rasker H. High prevalence and impact of rheumatic diseases is not reflected in the medical curriculum: The ILAR Undergraduate Medical Education in Rheumatology (UMER) 2000 Project. Together everybody achieves more. J Rheumatol. 1999; 25: $1037-1040$.

$5 \quad$ Smolen JS. Combating the burden of musculoskeletal diseases. Ann Rheum Dis. 2004; 63: 329.

6 Freedman KB, Bernstein J. Educational deficiencies in musculoskeletal medicine. J Bone Joint Surg Am. 2002; 84: 604-608.

7 Freedman KB, Bernstein J. The adequacy of medical school education in musculoskeletal medicine. J Bone Joint Surg Am. 1998; 80: $1421-1427$.

8 Holmstorm E, Engholm G. Musculo- skeletal disorders in relation to age and occupation in swedish construction workers. Am J Ind Med. $2003 ; 44: 377-384$.

9 Elliott AM, Smith BH, Penny KI, Smith WC, Chambers WA. The epidemiology of chronic pain in the community. Lancet.1999;354:12481252

10 Shiue HS, Lu WC, Chen CJ, Shih ST, Wu CS, Yang YC, Msk disorders among chinese restaurant cooks cohort, J Occup Health. 2008; 60:163-168.

11 Crombie IK, Croft PR, inton SJ, LeResche L, vonKroff M, editors. Epidemiology of Pain. Seattle: IASP press. 1999.

12 Finsen L, Christensen H, Bakke M. Musculoskeletal disorders among dentists and variation in dental work. Applied ergonomics. 1998; 29 (2): $119-125$.

13 Spector TD, Perry LA,Jubb RW. Endogenous sex steroid levels in women with generalized O.A. ClinRheumatol. 1991;10: 316-319.

14 Sowers M. Osteoarthritis and menopause. In Menopause: Biology and Pathobiology, eds, San DiagoAcademic press. 2000: 535-541.

15 Woolf AD, Akesson K. Understanding the burden of musculoskeletal conditions. BMJ. 2001; 322:1079-1080. 